\title{
Effects of Green Tea Intake on the Development of Coronary Artery Disease
}

\author{
Junko Sano, MD; Shigenobu Inami, MD; Koji Seimiya, MD; Takayoshi Ohba, MD; \\ Shunta Sakai, MD; Teruo Takano, MD*; Kyoichi Mizuno, MD
}

\begin{abstract}
Background Green tea, a popular beverage in Japan, contains many polyphenolic antioxidants, which might prevent atherosclerosis. This study was designed to determine whether the consumption of green tea is proportionately associated with a decreased incidence of coronary artery disease (CAD) and the cardiovascular and cerebrovascular prognosis.

Methods and Results The study group comprised 203 patients who underwent coronary angiography (109 patients with significant coronary stenosis and 94 patients without). Predictors for CAD were analyzed and the patients' cardiovascular and cerebrovascular events were followed. Green tea consumption was significantly higher in patients without $C A D$ than in those with $\mathrm{CAD}(5.9 \pm 0.5$ vs $3.5 \pm 0.3$ cups/day; $p<0.001)$. An inverse relationship between the intake of green tea and the incidence of CAD was observed $(p<0.001)$. The green tea intake per day was an independent predictor for $\mathrm{CAD}$ based on a multivariate logistic regression analysis (odds ratio: 0.84 and $95 \%$ confidence interval: $0.76-0.91$ ). In contrast, the green tea intake was not a predictor of cardiovascular and cerebrovascular events based on the Cox proportional hazard model.

Conclusions Green tea consumption was associated with a lower incidence of CAD in the present study population in Japan. Therefore, the more green tea patients consume, the less likely they are to have CAD. (Circ $J$ 2004; 68: 665-670)
\end{abstract}

Key Words: Antioxidant; Coronary artery disease; Green tea

$\mathbf{T}$ he oxidative modification of low-density lipoprotein (LDL) is a key event in early atherogenesis and it is responsible for cholesterol accumulation in the arterial wall! Because of the important role played by oxidized LDL, antioxidants may prevent the initiation and progression of coronary atherosclerosis and also reduce the incidence of coronary artery disease (CAD). Considerable epidemiologic, biochemical, and clinical evidence has accumulated in support of this hypothesis,-5 but the findings remain controversial. Flavonoids are a group of polyphenolic antioxidants present in fruits, vegetables, and beverages such as tea and wine. The dietary flavonoid intake is inversely related to the rate of mortality from CAD ${ }^{7,8}$ Despite a high intake of saturated fat in the French diet, the mortality rate from CAD in France is much lower than in other industrialized countries? The consumption of red wine, which contains a high concentration of flavonoids, may be one explanation for this French paradox!0,11

In Japan, the rate of cigarette smoking is still very high. Specifically, $32.7 \%$ of the adult Japanese population smoked in 2001, as reported by a Japan Tobacco, Inc news release. The LDL from cigarette smokers has been shown to be more susceptible to oxidative modification than LDL from nonsmokers! $!^{2}$ Nevertheless, the mortality rates from

(Received September 16, 2003; revised manuscript received April 13, 2004; accepted April 28, 2004)

Department of Medicine, Chiba Hokusoh Hospital, Nippon Medical School, Chiba, *First Department of Medicine, Nippon Medical School, Tokyo, Japan

Mailing address: Junko Sano, MD, Department of Medicine, Chiba Hokusoh Hospital, Nippon Medical School, 1715 Kamakari, Inbamura, Inba-gun, Chiba 270-1694, Japan. E-mail: sano-123@nms.ac. jp
CAD are much lower in Japan than in industrialized Western countries. ${ }^{13}$ The relatively lower plasma LDL concentration may account, in part, for the low CAD mortality rate. Furthermore, people in Japan drink green tea, which contains a high concentration of flavonoids, including catechins. Because green tea is made by steaming, not fermenting, fresh tea leaves, it contains more antioxidants than fermented teas such as oolong or black tea. In a recent study from the USA, tea consumption was inversely associated with cardiovascular mortality and overall mortality after acute myocardial infarction? However, so far only a few studies have suggested a weak inverse relationship between green tea intake and CAD! ${ }^{4}$ The 3 aims of this study were first, to clarify whether the consumption of green tea is associated with a decreased incidence of CAD in stable patients, second, to determine the relationship between the frequency of CAD and the total green tea intake, and third, to investigate whether the green tea intake is associated with future either cardiovascular or cerebrovascular events.

\section{Methods}

\section{Patients}

The study comprised 203 consecutive patients who underwent elective coronary angiography (CAG) between July 1, 1997 and December 31, 1997 in the Department of Medicine, Chiba Hokusoh Hospital, Nippon Medical School. Most of the patients underwent CAG because of typical or atypical chest pain, or abnormal ST-T changes; 7 underwent CAG during diagnostic catheterization for cardiomyopathy, and 1 underwent CAG during an assessment of valvular disease. Of the 203 patients, 109 had 
Table 1 Patient Characteristics

\begin{tabular}{lccc}
\hline \hline & $\begin{array}{c}\text { CAD } \\
(n=109)\end{array}$ & $\begin{array}{c}\text { No CAD } \\
(n=94)\end{array}$ & p value \\
\hline Age (years) & $60.0(0.9)$ & $57.5(1.1)$ & 0.08 \\
Male/female & $89(81.7 \%) / 20(18.3 \%)$ & $55(58.5 \%) / 39(41.5 \%)$ & $<0.001$ \\
Hypertension & $64(58.7 \%)$ & $40(42.5 \%)$ & 0.03 \\
Diabetes mellitus & $27(24.8 \%)$ & $15(16.0 \%)$ & 0.16 \\
Hyperlipidemia & $71(65.1 \%)$ & $56(59.6 \%)$ & 0.47 \\
Hyperuricemia & $33(30.3 \%)$ & $17(18.1 \%)$ & 0.05 \\
Obesity & $29(26.6 \%)$ & $17(18.1 \%)$ & 0.18 \\
Smoking & $74(67.9 \%)$ & $42(44.7 \%)$ & 0.001 \\
Family history of CAD & $36(33.0 \%)$ & $31(33.0 \%)$ & 1.00 \\
Plasma lipids & & & 0.81 \\
TC $(\mathrm{mg} / \mathrm{dl})^{*}$ & $207.9(3.9)$ & $204.8(4.0)$ & 0.93 \\
LDL-C $(\mathrm{mg} / \mathrm{dl})^{*}$ & $129.1(3.1)$ & $125.9(4.3)$ & 0.02 \\
HDL-C $(\mathrm{mg} / \mathrm{dl})^{*}$ & $46.6(1.2)$ & $51.5(1.5)$ & 0.10 \\
TG $(\mathrm{mg} / \mathrm{dl})^{\dagger}$ & $165.0(9.0)$ & $142.9(8.1)$ & \\
\hline
\end{tabular}

Data are reported as the mean (SE) or number (\%).

$C A D$, coronary artery disease; $T C$, total cholesterol; $L D L-C$, low-density lipoprotein-cholesterol; HDL-C, high-density lipoproteincholesterol; TG, triglycerides.

*To convert $\mathrm{mg} / \mathrm{dl}$ to $\mathrm{mmol} / \mathrm{L}$, multiply by 0.0259 , 'to convert $\mathrm{mg} / \mathrm{dl}$ to $\mathrm{mmol} / \mathrm{L}$, multiply by 0.0113 .

significant coronary stenoses ( 89 men, 20 women; mean age: $60.0 \pm 0.9$ years) and 94 patients did not ( 55 men, 39 women; mean age: $57.5 \pm 1.1$ years). The patients who had previously undergone coronary interventions, such as percutaneous transluminal coronary angioplasty, were considered to have significant coronary stenosis.

\section{Coronary Angiography}

Coronary angiography was performed using the Judkins method. At least 3 views of the right coronary artery and 4 views of the left coronary artery were obtained. Angiograms were interpreted by the consensus of 3 experienced cardiologists, who were unaware of the clinical data, using a semiquantitative grading system recommended by the American Heart Association $!^{15}$ Significant coronary stenosis was defined as a stenosis $>50 \%$ in the left main trunk or $>75 \%$ in the other major coronary arteries. Patients with $\mathrm{CAD}$ were defined as patients with at least 1 significant coronary stenosis.

\section{Risk Factors}

Hypertension was defined as systolic blood pressure $>140 \mathrm{mmHg}$ or diastolic blood pressure $>90 \mathrm{mmHg}$ or treatment with antihypertensive drugs. Brachial blood pressure was measured at least 3 times using a calibrated mercury sphygmomanometer while the patient was supine. Hyperlipidemia was defined as a serum total cholesterol concentration $>220 \mathrm{mg} / \mathrm{dl}(5.698 \mathrm{mmol} / \mathrm{L})$ or triglyceride concentration $>150 \mathrm{mg} / \mathrm{dl}(1.695 \mathrm{mmol} / \mathrm{L})$, or treatment with lipid-lowering agents. Diabetes mellitus was defined according to World Health Organization criteria!6 Hyperuricemia was defined as a uric acid concentration $>7.5 \mathrm{mg} / \mathrm{dl}$ in men or $>6.0 \mathrm{mg} / \mathrm{dl}$; in women, or drug therapy. The patients who smoked regularly during the previous 12 months were classified as smokers. The height and weight of each patient was measured, from which the body mass index (BMI) was calculated. Obesity was defined as a BMI $\geq 25.0 \mathrm{~kg} / \mathrm{m}^{2} .17$

\section{Lipids}

Fasting blood samples were obtained during the hospitalization for CAG. The total cholesterol concentration was determined using the cholesterol oxidase-3,5-dimethoxy-
N-ethyl-N-(2-hydroxy-3-sulfopropyl)-aniline method. The high-density lipoprotein cholesterol (HDL-C) concentration was measured using the enzymatic selective inhibition method and the triglyceride concentration was measured using the enzymatic method. LDL-cholesterol concentration was calculated using Friedewald's method 18 None of the patients had type III hyperlipidemia.

\section{Assessment of the Intake of Green Tea and Other Beverages}

All patients were interviewed just before CAG regarding their typical daily intake of green tea, vitamin supplementation, and the consumption of other beverages including red wine. Tea intake is reported as cups/day $(1 \mathrm{cup}=120 \mathrm{ml})$. This study was approved by the Institutional Review Board of the hospital. Informed consent was obtained from all patients.

\section{Cardiovascular and Cerebrovascular Events}

The occurrences of cardiovascular and cerebrovascular events and all causes of death were followed up through October 30, 2003. The cardiovascular events included myocardial infarction and unstable angina. The cerebrovascular events included cerebral infarction, transient ischemic attack, which needed hospitalization, and cerebrovascular hemorrhage. The diagnosis of each disease and cause of death was verified from the medical records.

\section{Statistical Analysis}

The sample size was based on the assumption from our preliminary study that the average intake of green tea of the patients with $C A D$ was $4 \pm 4$ cups/day and without $C A D$ was $6 \pm 4$ cups/day. According to that estimation, we deduced the minimal sample size for this study to be 170 with 0.05 of two-sideda and $90 \%$ of power. Continuous variables were reported as the mean $\pm \mathrm{SE}$ and analyzed by the Wilcoxon rank-sum test. Categorical variables were analyzed using Fisher's exact probability test. The relationship between the daily intake of green tea and the incidence of CAD was analyzed using the Cochran-Mantel-Haenszel test. An analysis of variance was determined for the relationships between daily green tea intake and age or plasma lipid concentration. The predictors of CAD were analyzed by 


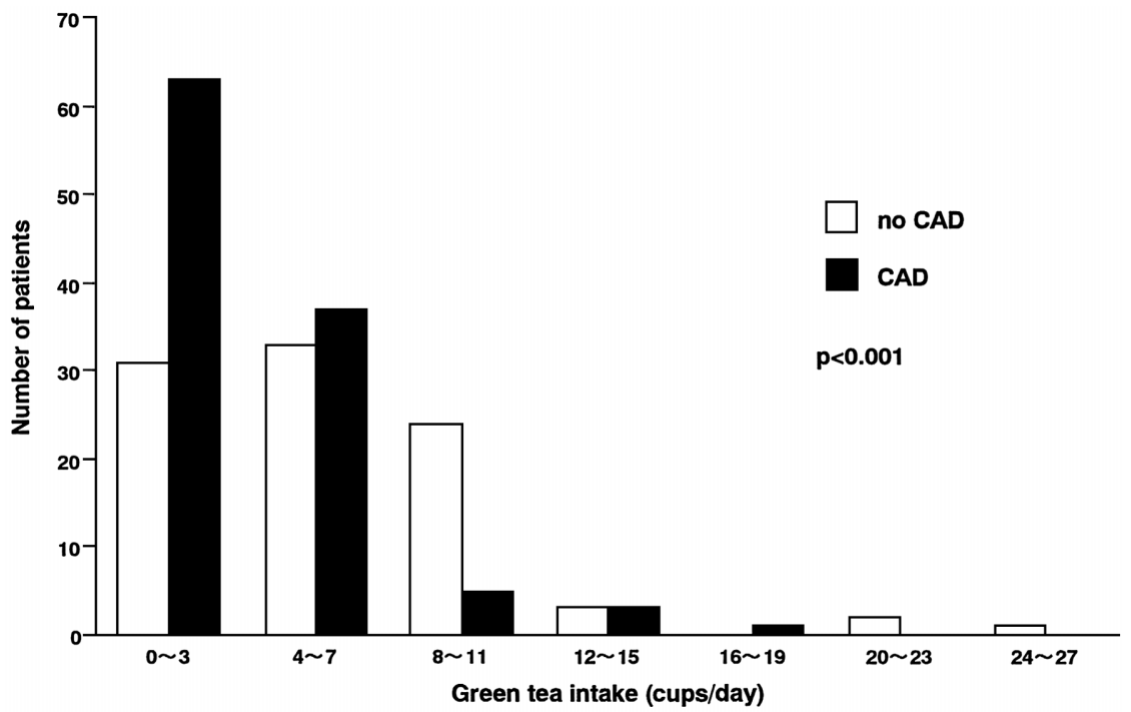

Fig 1. Relationship between green tea intake and coronary artery disease (CAD): the more green tea patients consume, the less likely they are to have CAD $(\mathrm{p}<0.001)$.

univariate and multivariate logistic regression analyses using the following parameters: gender, hypertension, diabetes mellitus, obesity, smoking habits, family history of $\mathrm{CAD}$, age, daily intake of green tea, triglyceride, LDL- and HDL-C concentrations. The predictors of cardiovascular and cerebrovascular events were analyzed by the Cox proportional hazards regression analysis using the following parameters: gender, hypertension, diabetes mellitus, obesity, smoking habits, family history of CAD, left ventricular ejection fraction, number of diseased coronary vessels, age, daily intake of green tea, triglyceride, LDL- and HDL-C concentrations, and HMG-CoA reductase inhibitors and the anti-platelet drug intake. Gender, hypertension, diabetes mellitus, obesity, smoking habits, and family history of $\mathrm{CAD}$ were analyzed as categorical variables, and age, daily intake of green tea, left ventricular ejection fraction, number of diseased coronary vessels and triglyceride, LDL- and HDL-C concentrations were analyzed as continuous variables. A value for $\mathrm{p}<0.05$ was considered statistically significant. Statistical analyses were performed using SAS for Windows version 6.12 (SAS Institute, Cary, NC, USA).

\section{Results}

\section{Patient Characteristics}

Table 1 summarizes the baseline characteristics of the patients. The percentage of men, the incidence of hypertension and the frequency of smoking were all significantly higher in the group of patients with CAD than in the group without CAD. The HDL-C concentration was significantly higher in the patients without $\mathrm{CAD}$ than in the patients with CAD.

\section{Daily Intake of Green Tea and Other Beverages}

The mean daily intake of green tea in patients with $\mathrm{CAD}$ was $3.5 \pm 0.3 \mathrm{cups} /$ day compared with $5.9 \pm 0.5 \mathrm{cups} /$ day in patients without CAD $(\mathrm{p}<0.001)$. The relationship between green tea intake and the number of patients with CAD is shown in Fig 1. The data indicate that the more green tea that patients drink, the less likely they are to have CAD $(\mathrm{p}<0.001)$. The patient characteristics and the daily green tea intake are summarized in Table 2 . The mean daily intake of green tea was significantly higher in women than in men. There was no relationship between age or plasma
Table 2 Patient Characteristics and Daily Green Tea Intake

\begin{tabular}{|c|c|c|c|}
\hline & No. of patients & $\begin{array}{l}\text { Green tea intake } \\
\text { (cups/day) }\end{array}$ & $p$ value \\
\hline \multicolumn{4}{|l|}{ Gender } \\
\hline Male & 144 & $4.3(0.3)$ & 0.04 \\
\hline Female & 59 & $5.3(0.5)$ & \\
\hline \multicolumn{4}{|c|}{ Hypertension } \\
\hline+ & 104 & $4.3(0.3)$ & 0.55 \\
\hline 0 & 99 & $5.0(0.5)$ & \\
\hline \multicolumn{4}{|c|}{ Diabetes mellitus } \\
\hline+ & 42 & $3.9(0.6)$ & 0.08 \\
\hline 0 & 161 & $4.8(0.3)$ & \\
\hline \multicolumn{4}{|c|}{ Hyperlipidemia } \\
\hline+ & 127 & $5.1(0.4)$ & 0.06 \\
\hline 0 & 76 & $3.8(0.3)$ & \\
\hline \multicolumn{4}{|c|}{ Hyperuricemia } \\
\hline+ & 50 & $4.7(0.6)$ & 0.76 \\
\hline 0 & 153 & $4.6(0.3)$ & \\
\hline \multicolumn{4}{|l|}{ Obesity } \\
\hline+ & 46 & $3.8(0.5)$ & 0.10 \\
\hline 0 & 157 & $4.8(0.3)$ & \\
\hline \multicolumn{4}{|l|}{ Smoking } \\
\hline+ & 116 & $4.3(0.4)$ & 0.09 \\
\hline 0 & 87 & $5.0(0.4)$ & \\
\hline \multicolumn{4}{|c|}{ Family history of $C A D$} \\
\hline+ & 67 & $4.6(0.5)$ & 0.85 \\
\hline 0 & 136 & $4.6(0.4)$ & \\
\hline
\end{tabular}

Data are reported as the mean (SE) or number. CAD, coronary artery disease.

lipid concentration and the daily intake of green tea. Sixtyeight patients drank alcohol either everyday or every other day. There was no significant difference in HDL-C between drinkers and non-drinkers $(51.0 \pm 1.8 \mathrm{mg} / \mathrm{dl}$ and $48.0 \pm$ $1.2 \mathrm{mg} / \mathrm{dl}$, respectively, $\mathrm{p}=0.16$; data not shown). None of the patients took vitamin supplements, such as vitamin $\mathrm{E}$ or $\mathrm{C}$, and none of the patients regularly drank red wine or black tea.

\section{Predictors of Coronary Disease}

The predictors of CAD were identified by logistic regression analysis (Table 3). Based on a univariate analysis, the significant predictors of CAD were male gender, hypertension, smoking habits, green tea intake and HDL-C concentration. The green tea intake and HDL-C concentra- 
Table 3 Predictors of Coronary Artery Disease Based on Univariate and Multivariate Logistic Regression Analyses

\begin{tabular}{|c|c|c|c|c|c|}
\hline \multirow{2}{*}{ Variable } & \multirow{2}{*}{$\begin{array}{l}\text { No. of patients } \\
\text { with } C A D\end{array}$} & \multicolumn{2}{|c|}{ Univariate } & \multicolumn{2}{|c|}{ Multivariate } \\
\hline & & Odds ratio $(95 \% \mathrm{CI})$ & $p$ value & Odds ratio $(95 \% \mathrm{CI})$ & $p$ value \\
\hline \multicolumn{6}{|l|}{ Gender } \\
\hline Female & 20 & 1.00 & & 1.00 & \\
\hline Male & 89 & $3.16(1.69-6.05)$ & $<0.001$ & $1.77(0.76-4.13)$ & 0.18 \\
\hline \multicolumn{6}{|l|}{ Hypertension } \\
\hline 0 & 45 & 1.00 & & 1.00 & \\
\hline+ & 64 & $1.92(1.10-3.38)$ & 0.02 & $1.52(0.78-2.99)$ & 0.22 \\
\hline \multicolumn{6}{|l|}{ Diabetes mellitus } \\
\hline 0 & 82 & 1.00 & & 1.00 & \\
\hline+ & 27 & $1.73(0.87-3.57)$ & 0.12 & $1.19(0.53-2.71)$ & 0.68 \\
\hline \multicolumn{6}{|l|}{ Obesity } \\
\hline 0 & 80 & 1.00 & & 1.00 & \\
\hline+ & 29 & $1.59(0.86-2.96)$ & 0.14 & $1.16(0.56-2.42)$ & 0.69 \\
\hline \multicolumn{6}{|l|}{ Smoking habits } \\
\hline 0 & 35 & 1.00 & & 1.00 & \\
\hline+ & 74 & $2.62(1.49-4.67)$ & 0.001 & $1.99(0.95-4.20)$ & 0.07 \\
\hline \multicolumn{6}{|c|}{ Family history of CAD } \\
\hline 0 & 73 & 1.00 & & 1.00 & \\
\hline+ & 36 & $1.00(0.56-1.81)$ & 0.99 & $0.84(0.42-1.68)$ & 0.63 \\
\hline Age & & $1.03(1.00-1.05)^{*}$ & 0.08 & $1.03(1.00-1.07) *$ & 0.10 \\
\hline Green tea intake & & $0.83(0.76-0.90)^{\dagger}$ & $<0.001$ & $0.84(0.76-0.91)^{\dagger}$ & 0.001 \\
\hline$T G$ & & $1.00(1.00-1.01)^{\frac{1}{+}}$ & 0.08 & $1.00(1.00-1.01)^{\frac{\hbar}{*}}$ & 0.28 \\
\hline$L D L-C$ & & $1.00(1.00-1.01)^{\ddagger}$ & 0.54 & $1.01(1.00-1.02)^{\ddagger}$ & 0.21 \\
\hline$H D L-C$ & & $0.97(0.95-0.99)^{\ddagger}$ & 0.01 & $0.99(0.96-1.02)^{\ddagger}$ & 0.60 \\
\hline
\end{tabular}

$C A D$, coronary artery disease; $C I$, confidence interval; TG, triglycerides; $L D L-C$, low-density lipoprotein-cholesterol; HDL-C, high-density lipoprotein-cholesterol.

*Per 1-year old increment; $†$ per 1-cup/day increment; $\$ 1$-mg/dl increment.

tion were inversely related to CAD. The only independent variable identified by multivariate regression analysis was the green tea intake $(\mathrm{p}<0.001)$. The odds ratio for green tea intake per cup/day was 0.84 . Green tea intake was inversely associated with the presence of CAD.

\section{Gender Difference in Predictors of Coronary Disease}

The percentage of men was significantly higher in the group of patients with CAD than in the group without CAD. We analyzed the data in each gender to exclude any gender-related bias. In male patients, the green tea intake was significant higher in those without CAD than with CAD, $6.1 \pm 0.6$ cups/day and $3.2 \pm 0.3$ cups/day, respectively $(p<0.001)$. In female patients, green tea intake was higher in those without $\mathrm{CAD}$ than with $\mathrm{CAD}$, but not significantly, $5.7 \pm 0.6$ cups/day and $4.5 \pm 0.9$, respectively $(\mathrm{p}=0.27)$. The predictors of $\mathrm{CAD}$ were analyzed by logistic regression analysis in each gender. In male patients, the only independent variable identified by multivariate regression analysis was green tea intake (odds ratio (OR): $0.81,95 \%$ confidence interval: $0.72-0.91)$. In female patients, there was no independent variable identified by multivariate regression analysis.

\section{Cardiovascular and Cerebrovascular Events}

The mean follow up period was $4.9 \pm 0.1$ years and the follow up rate was $93.4 \%$. The number of cardiovascular events was 38: 34 with unstable angina, 1 non-fatal myocardial infarction, 1 fatal myocardial infarction, and 2 sudden cardiac deaths. The number of cerebrovascular events was 7, and all of them were ischemic stroke. According to age-, coronary risk factors-, and medication-adjusted Cox proportional hazards regression analyses, there was no significant relationship between the occurrence of cardiovascular and cerebrovascular events, cardiovascular death and green tea consumption, $p=0.097$ and $p=0.891$, respectively. There was also no significant relationship between cardiovascular events and green tea consumption in either all patients or in the patients with cardiovascular disease $(\mathrm{p}=0.137$ and $\mathrm{p}=$ 0.172 , respectively). Among the patients with $\mathrm{CAD}$, the mean green tea consumption in patients with cardiovascular events was $3.7 \pm 0.5$ cups/day and without events was $3.4 \pm 0.4$ cups/day $(\mathrm{p}=0.67)$

\section{Discussion}

The present study showed a strong inverse association between green tea consumption and CAD. Furthermore, we demonstrated that higher the green tea intake, the less CAD occurred. There have been few reports concerning the relationship between green tea intake and angiographically proven CAD. Hirano et al reported only $29 \%$ of patients drank $>3$ cups green tea/day!4 Approximately 50\% of Japanese aged over 40 years usually drink $\geq 4$ cups/day!9,20 In the present study, $47 \%$ of the patients drank $>3$ cups/day, which is comparable with the general Japanese population. The lack of an association between green tea consumption and CAD in Hirano's report may be due to their subjects' low average intake of green tea. Sasaguki et al analyzed the data in each gender group, and green tea consumption was inversely associated with CAD only in men without diabetes mellitus, but not in women? ${ }^{2}$ We also analyzed the data in each gender and found a significant relationship between the green tea intake and CAD in men alone. No significant relationship was observed between green tea intake and $\mathrm{CAD}$ in women, but the green tea consumption tended to be higher in women without CAD than in those with CAD. The lack of an association in women in the present study may be related to the low number of female patients. After adjusting for gender, age, and coronary risk factors in all patients in the multivariate logistic analysis, green tea consumption was analyzed as a predictor of 
CAD. Green tea consumption was inversely associated with CAD unrelated to gender.

Japanese have a low incidence of CAD. A low plasma cholesterol concentration was considered to be one explanation, but the cholesterol concentration has increased in Japanese over the past 3 decades.22 In addition, the smoking rate is higher in Japan than in other industrialized countries. Even under these circumstances, the incidence of CAD is still low. Genetic differences could be one reason and the environment or living habits may also affect the incidence of CAD. In the Seven Countries Study, there were strong associations between serum total cholesterol and CAD mortality in the USA and Northern Europe, but much weaker associations in Japan.23 It is difficult to explain the low incidence of CAD based on a low cholesterol concentration alone. Hertog et al reported in The Seven Countries Study that the average intake of antioxidant flavonoids is inversely associated with the mortality rate from CAD 24 Japan has a higher per capita flavonoid intake than other industrialized countries, because of the high rate of tea consumption, generally green tea ${ }^{24}$ In a recent study, tea consumption was inversely associated with cardiovascular mortality and overall mortality after acute myocardial infarction? However, so far no study on green tea, which contains more antioxidants than fermented teas such as oolong or black tea, has been made in regard to the cardiovascular and cerebrovascular prognosis. Our study revealed that the green tea intake is an independent predictor for CAD. However, no relationship was found between green tea intake and cardiovascular events. This is the first report about green tea consumption and the cardiovascular prognosis in stable patients. However, the sample size was small. We need to perform further studies on a larger number of patients.

Previous studies have suggested that tea consumption decreases atherosclerosis. Tijburg et al reported that the ingestion of green tea reduced atherosclerotic plaque formation by $31 \%$ in cholesterol-fed rabbits ${ }^{25}$ and Geleijnse et al reported an inverse relationship between tea intake with the presence of long $(>5 \mathrm{~cm})$ calcified plaques in the abdominal aorta26 The ORs decreased from 0.54 for patients drinking $1-2$ cups of tea to 0.31 for patients drinking more than 4 cups per day.

The strong antioxidant property of tea may be one explanation of its preventive effect on the development of CAD. Because green tea is made by steaming, not fermenting fresh tea leaves, it contains more antioxidants than fermented teas such as oolong or black tea. Green tea contains high concentrations of flavonoids, especially catechins. They have strong antioxidant properties both in vitro and in vivo $^{27-31}$ and they inhibit the oxidation of LDL to a higher degree than vitamin E. ${ }^{27}$ Ishikawa et al reported that the time required for LDL oxidation increased significantly in patients consuming $750 \mathrm{ml}$ of black tea/day ( 5 cups/day) for 4 weeks $3{ }^{31}$ In the present study, the daily intake of green tea was $5.9 \mathrm{cups} /$ day in patients without CAD and it was expected to have an antioxidant activity in vivo.

Improvement in endothelial dysfunction by tea may be other explanation of how it prevents the development of CAD. Endothelial dysfunction may contribute to the pathogenesis of atherosclerosis. Duffy et al reported the consumption of $900 \mathrm{ml}$ black tea daily for 4 weeks reversed endothelial dysfunction in patients with CAD 32

Green tea also has other properties that may prevent the development of CAD. Specifically, green tea has anti- hyperlipidemic (lowering LDL-, increasing HDL-C) ${ }^{19,33,34}$ properties. Furthermore, green tea suppresses increased plasma glucose concentration, 35 and inhibits platelet aggregation 36,37 However, in the present study, no association was observed between green tea consumption and plasma lipid concentrations, or the presence of diabetes mellitus.

According to the univariate analysis, male, hypertension, and smoking were predictors of CAD, but diabetes mellitus was not and age had only a weak association, the reason being that the sample size of this study was small. The only independent predictor of CAD from the multivariate logistic regression analysis was the daily intake of green tea; traditional coronary risk factors were not investigated as independent predictors in this study. The reason for this may be multi-correlations among coronary risk factors in the present study population. All of the study subjects underwent CAD because of a suspected diagnosis of CAD. Patients with coronary risk factors tend to undergo exercise electrocardiography or ambulatory electrocardiography in our hospital, and of them, the patients with abnormal ST-T change usually undergo CAG. In the present study the percentages of patients with each coronary risk factor were higher than would ordinarily occur $3^{38}$ The high percentages of patients with multiple risk factors would cause multicorrelations among the risk factors. We need to study a larger sample size and also have more accurate information about green tea intake and the incidence of CAD among the general population.

A strong relationship was observed between green tea consumption and CAD, but we cannot rule out the possibility that patients who frequently take green tea may also prefer traditional Japanese style foods. Traditional Japanese style foods frequently contain fish, vegetables, and soybeans, which may also have anti-atherosclerotic properties.

In conclusion, the ingestion of green tea was found to be associated with a lower incidence of CAD in our study population in Japan. As a result, the higher the green tea intake, the less likely CAD is to develop.

\section{References}

1. Steinberg D, Parthasarathy S, Carew TE, Khoo JC, Witztem JL. Beyond cholesterol: Modifications of low-density lipoprotein that increase its atherogenicity. N Engl J Med 1989; 320: 915-924.

2. Kita T, Nagano Y, Yokode M, Yokode M, Ishii K, Kume N, et al. Probucol prevents the progression of atherosclerosis in Watanabe heritable hyperlipidemic rabbit, an animal model for familial hypercholesterolemia. Proc Natl Acad Sci USA 1987; 84: 5928-5931.

3. Stephens NG, Parsons A, Schofield PM, Kelly F, Cheeseman K, Mitchinson M, et al. Randomised controlled trial of vitamin E in patients with coronary disease: Cambridge Heart Antioxidant Study (CHAOS). Lancet 1996; 347: 781-786.

4. Boaz M, Smetana S, Weinstein T, Matas Z, Gafter U, Iaina A, et al. Secondary prevention with antioxidants of cardiovascular disease in endstage renal disease (SPACE): Randomised placebo-controlled trial. Lancet 2000; 356: $1213-1218$.

5. Fang JC, Kinlay S, Beltrame J, Hikiti H, Wainstein M, Behrendt D, et al. Effect of vitamins $\mathrm{C}$ and $\mathrm{E}$ on progression of transplant-associated arteriosclerosis: A randomised trial. Lancet 2002; 359: $1108-$ 1113.

6. Heart Protection Study Collaborative Group. MRC/BHF Heart Protection Study of antioxidant vitamin supplementation in 20536 highrisk individuals: A randomised placebo-controlled trial. Lancet 2002; 360: $23-33$.

7. Hertog MGL, Feskens EJM, Hollman PCH, Katan MB, Kromhout D. Dietary antioxidant flavonoids and risk of coronary heart disease: The Zetphen Elderly Study. Lancet 1993; 342: 1007-1011.

8. Mukamal KJ, Maclure M, Muller JE, Sherwood JB, Mittleman MA. Tea consumption and mortality after acute myocardial infarction. Circulation 2002; 105: 2476-2481.

9. Renaud S, de Lorgeril M. Wine, alcohol, platelets, and the French 
paradox for coronary heart disease. Lancet 1992; 339: 1523-1526.

10. Frankel EN, Kanner J, German JB, Parks E, Kinsella JE. Inhibition of oxidation of human low-density lipoprotein by phenolic substances in red wine. Lancet 1993; 341: 454-457.

11. Kondo K, Matsumoto A, Kurata H, Tanahashi H, Koda H, Amachi $\mathrm{T}$, et al. Inhibition of oxidation of low-density lipoprotein with red wine. Lancet 1994; 344: 1152.

12. Harats D, Ben-Naim M, Dabach Y, Hollander G, Stein O, Stein Y. Cigarette smoking renders LDL susceptible to peroxidative modification and enhanced metabolism by macrophages. Atherosclerosis 1989; 79: 245-252.

13. Tanabe N, Saito R, Sato T, Hayashi S, Toyoshima H, Seki N, et al. Event rates of acute myocardial infarction and coronary deaths in Niigata and Nagaoka cities in Japan. Circ J 2003; 67: 40-45.

14. Hirano R, Momiyama $\mathrm{Y}$, Takahashi R, Taniguchi H, Kondo K, Nakamura $\mathrm{H}$, et al. Comparison of green tea intake in Japanese patients with and without angiographic coronary artery disease. Am J Cardiol 2002; 90: 1150-1153.

15. Austen WG, Edwards JE, Frye RL, Gensini GG, Gott VL, Griffith LSC, et al. A reporting system on patients evaluated for coronary artery disease: Report of the Ad Hoc Committee for Grading of Coronary Artery Disease, Council on Cardiovascular Surgery, American Heart Association. Circulation 1995; 51: 5-40.

16. Alberti KG, Zimmet PZ. Definition, diagnosis and classification of diabetes mellitus and its complications. Part 1: Diagnosis and classification of diabetes mellitus: Provisional report of a WHO consultation. Diabet Med 1998; 15: 539-553.

17. The Examination Committee of Criteria for 'Obesity Disease' in Japan, Japan Society for the Study of Obesity. New criteria for 'obesity disease' in Japan. Circ J 2002; 66: 987-992.

18. Friedewald WT, Levy RI, Fredrickson DS. Estimation of the concentration of low-density lipoprotein cholesterol in plasma, without use of the preparative ultracentrifuge. Clin Chem 1972; 18: 499-502.

19. Imai K, Nakachi K. Cross sectional study of effects of drinking green tea on cardiovascular and liver diseases. BMJ 1995; 310: 693-696.

20. Sato Y, Nakatsuka H, Watanabe T, Hisamichi S, Shimizu H, Fujisaku S, et al. Possible contribution of green tea drinking habits to the prevention of stroke. Tohoku J Exp Med 1989; 157: 337-343.

21. Sakazuki S, Kodama H, Yoshimasu K, Liu Y, Washio M, Tanaka K, et al. Relation between green tea consumption and the severity of coronary atherosclerosis among Japanese men and women. Ann Epidemiol 2000; 10: 401-408.

22. Research committee on serum lipid level survey 1990 in Japan. Current state of and recent trends in serum lipid levels in the general Japanese population. J Atheroscler Thromb 1996; 2: 122-132.

23. Verschuren WMM, Jacobs DR, Bloemberg BPM, Kromhout D, Menotti A, Aravanis C, et al. Serum total cholesterol and long-term coronary heart disease mortality in different cultures: Twenty-fiveyear follow-up of the Seven Countries Study. JAMA 1995; 274: $131-136$

24. Hertog MGL, Kromhout D, Aravanis C, Blackburn H, Buzina R,
Fidanza F, et al. Flavonoid intake and long-term risk of coronary heart disease and cancer in the Seven Countries Study. Arch Intern Med 1995; 155: 381-386.

25. Tijburg LBM, Wiseman SA, Meijer GW, Weststrate JA. Effects of green tea, black tea and dietary lipophlic antioxidants on LDL oxidizability and atherosclerosis in hypercholesterolaemic rabbits. Atherosclerosis 1997; 135: 37-47.

26. Geleijnse JM, Launer LJ, Hofman A, Pols HA, Witteman JCM. Tea flavonoids may protect against atherosclerosis: The Rotterdam Study. Arch Intern Med 1999; 159: 2170-2174.

27. Okuda T, Kimura Y, Yoshida T, Hatano T, Okuda H, Arichi S. Studies on the activities of tannins and related compounds from medicinal plants and drugs. I: Inhibitory effects of lipid peroxidation in mitochondria and microsomes of liver. Chem Pharm Bull 1983; 31: $1625-1631$.

28. Yoshino K, Tomita I, Sano M, Oguni I, Hara Y, Nakano M. Effects of long-term dietary supplement of tea polyphenols on lipid peroxide levels in rats. Age 1994; 17: 79-85.

29. Sano M, Takahashi Y, Yoshino K, Shimoi K, Nakamura Y, Tomita I, et al. Effects of tea (Camellia sinensis L.) on lipid peroxidation in rat liver and kidney: A comparison of green and black tea feeding. Biol Pharm Bull 1995; 18: 1006-1008.

30. Serafini M, Ghiselli A, Ferro-Luzzi A. Red wine, tea, and antioxidants. Lancet 1994; 344: 626.

31. Ishikawa T, Suzukawa M, Ito T, Yoshida H, Ayaori M, Nishiwaki M, et al. Effects of tea flavonoid supplementation on the susceptibility of low-density lipoprotein to oxidative modification. Am J Clin Nutr 1997; 66: $261-266$.

32. Duffy SJ, Keaney JF, Holbrook M, Gokce N, Swerdloff PL, Frei B, et al. Short- and long-term black tea consumption reverses endothelial dysfunction in patients with coronary artery disease. Circulation 2001; 104: 151-156.

33. Muramatsu K, Fukuyo M, Hara Y. Effect of green tea catechins on plasma cholesterol level in cholesterol-fed rats. J Nutr Sci Vitaminol 1986; 32: 613-622.

34. Maron DJ, Lu GP, Cai NS, Wu ZG, Li YH, Chen H, et al. Cholesterol-lowering effect of theaflavin-enriched green tea extract: A randomized controlled trial. Arch Intern Med 2003; 163: 1448 1453.

35. Matsumoto N, Ishigaki F, Ishigaki A, Iwashina H, Hara Y. Reduction of blood glucose levels by tea catechin. Biosci Biotechnol Biochem 1993; 57: 525-527.

36. Sagesaka-Mitane Y, Miwa M, Okada S. Platelet aggregation inhibitors in hot water extract of green tea. Chem Pharm Bull (Tokyo) 1990; 38: 790-793.

37. Kang WS, Lim IH, Yuk DY, Chung KH, Park JB, Yoo HS, et al. Antithrombotic activities of green tea catechins and (-)-epigallocatechin gallate. Thromb Res 1999; 96: 229-237.

38. Ministry of Health and Welfare. The third national survey of circulatory disorders 1980. Tokyo: Japan Heart Foundation, 1983 (in Japanese). 